\title{
Elektronik Sağlık Kayıt Sistemlerinin Kütüphanelerle Bütünleştirilmesi
}

\author{
Integrating Libraries to Electronic \\ Health Record Systems
}

\section{Ayşen KÜYÜK*, Aslan KAPLAN"*, Ali YILMAZ***}

Öz

Sağlık hizmetlerinde önemli bir yeri olan bilginin miktarındaki ve çeşitliliğindeki artış, kullanıııların başa çıkamayacağı boyutlara ulaşmıştır. Artan bilgi miktarı karşısında değişen kullanıcı gereksinimlerini karşılayabilmek amacıyla, "elektronik sağlık kayıt sistemleri" geliştirilmeye başlanmıştır. Elektronik kütüphanelerle bütünleşen "elektronik sağlık kayıt sistemleri" hasta bilgilerinin yanısıra, sağılk çalışanlarının tanı ve tedavi için gereksinim duydukları tıbbi literatüre de ulaşabilmelerine olanak sağlamaktadır. Hasta bilgilerini, aynı sistem üzerinden erişilen bilgi kaynakları ile karşılaştırıp değerlendirmek sağlık çalışanlarına zaman kazandırmakta ve hastanın tedavisinde hızlı ve doğru karar almalarına yardımcı olmaktadır. "Elektronik sağlık kayıt sistemleri" kütüphanelere ve kütüphanecilere bağlı bulundukları sağlık kurumu içerisinde daha aktif roller yüklemektedir.

Anahtar sözcükler: Elektronik sağlık kayıtları, Elektronik kütüphaneler, Tıp kütüphaneleri, Tıp bilgi merkezleri.

\footnotetext{
Abstract

The increase of volume and variety of information, which in turn has an important role in health services, reached to an explosive bulk, that can hardly be managable for the users. In order to meet users' needs under these conditions, electronic health record systems were developed. Electronic health record systems integrated with electronic libraries allow clinicians, along with the patient information, also to

*Uzman Kütüphaneci; Hacettepe Üniversitesi Tıp Merkez Kütüphanesi Hacettepe 06100 Ankara (akuyuk@hacettepe.edu.tr).

** Yrd. Doç. Dr.; Hacettepe Üniversitesi Sağlık Meslek Yüksekokulu Tıbbi Dokümantasyon ve Sekreterlik Hacettepe 06100 Ankara (akaplan@hacettepe.edu.tr).

*** Öğr. Gör.; Hacettepe Üniversitesi Sağlık Meslek Yüksekokulu Tıbbi Dokümantasyon ve Sekreterlik Hacettepe 06100 Ankara (aly@hacettepe.edu.tr).
} 
access medical literature they would need for treatment. By comparing patient information with current information sources concerning relevant medical advances and thus performing evaluations being based on such comparisons help clinicians to save time and make fast and accurate decisions. On the other hand, the use of electronic health record systems require more active roles from medical libraries and their librarians within the framework of their parent organisation.

Keywords: Electronic health records, Electronic libraries, Medical libraries, Medical information centers.

\section{Giriş}

Alvin Toffler, "Üçüncü Dalga" adlı eserinde toplumsal gelişmeyi birincisi "tarım devrimi", ikincisi "sanayi devrimi”, üçüncüsü "bilgi devrimi” olmak üzere birbirini izleyen bir "dalga" metaforu ile açıklamaktadır (Bozkurt, 1997, s. 20). Söz konusu metafordaki üçüncü dalganın yarattığı bilgi toplumunda, bilgi, ekonomik bir değer olarak ön plana çıkmakta, iletişim teknolojilerinin de yardımıyla hızla yayılmakta ve örgüt yapıları bilgiyi temel alan bir değişim göstermektedir.

Örgütler çevrelerinden gelen taleplere, gelişen teknolojiye, değişen politikalara ve örgütsel davranışlara uyum sağlamak zorundadır. Örgütlerin varlıklarını devam ettirebilmeleri buna bağlıdır (Dieneman ve Van De Castle, 2002, ss. 303-305). Son yıllarda tüm alanlarda olduğu gibi sağlık sektöründe yer alan örgütlerde de hızlı bir değişim ve dönüşüm yaşanmaktadır. Bu değişimi şu şekilde özetlemek mümkündür: 1900-1945 yılları arasında sağlık hizmetlerinde gelişmeler halk sağlığı alanında yoğunlaşırken, teknoloji kullanımı bu dönemde henüz başlangıç aşamasındadır.

1945-1970 yılları arasında sağlık hizmetlerinde teknoloji yaygın olarak kullanılmaya başlanmış, tanı ve tedavide, cerrahi yöntemler ve yaklaşımlarda yeni teknikler geliştirilmiştir. Yeni Rönesans (Neo-Rönasans) olarak tanımlanan bu dönemde daha önce tedavi edilemeyen birçok hastalığın tedavisi mümkün olmuştur. Sonraki yirmi yılda ise sağlık hizmetlerinde yüksek teknolojinin kullanıldığı ve bunun getirdiği maliyetlerin de en çok tartışılan konular arasında olduğu görülmektedir (Sloane ve Sloane, 1992, ss. 211214).

1990'lardan itibaren sağılı hizmetlerinde çok hızlı bir değişim ve gelişim yaşanmış, sonucunda bu alanda verimlilik ve kalite konuları önem kazanmış, sağlık hizmetlerinin verilmesinde yeni modeller geliştirilmiş, sağlık kurumları yeniden yapılandırılmış, sağlık hizmetlerinin sunumu ile klinik süreçler yeniden biçimlendirilmiş ve geleneksel uygulamalar yerlerini yeni uygula- 
malara bırakmıştır. Standartlar, klinik uygulama kılavuzları, kanıta dayalı tıp (evidence based medicine), klinik performans yönetimi, klinik sonuçların ölçümü ve risk değerlendirme, tıbbi bilişim (medical informatic), tele-tıp, internet uygulamaları bu dönemde yaşanan gelişmelere verilebilecek örneklerden sadece birkaçıdır (Erdoğan, 2000, s. 1).

Sağlık hizmetlerinde bilginin ve bilgi teknolojilerinin yoğun olarak kullanılması ve buna bağı olarak yukarıda belirtilen yeni kavramların ve uygulamaların gelişmesi bu alanda bilgi yönetiminin önemini artırmıştır.

Amerika Birleşik Devletleri (ABD)'nde Tıp Enstitüsü (Institute of MedicineIOM) tarafından yapılan çalışmada mevcut sağlık kayıt sistemlerinin sağlık hizmetlerinde yaşanan değişimlerin sonucu ortaya çıkan beklentileri karşılayamayacağı ortaya konulmuştur. Söz konusu çalışmada, ayrıca sağlık bakımı ve hizmeti veren tüm personelin, hastanın tedavisi sırasında gerekli olacak her türlü bilgiye en kısa sürede ulaşmasını sağlayacak, bireylerin yaşam boyu sağlık kayıtlarını kapsayacak "elektronik sağlık/hasta kayıtları"na gereksinim olduğu belirtilmiştir (Dick, Steen ve Detmer, 1997, s. 69).

\section{Elektronik Sağlık Kayıt Sistemleri}

"Elektronik sağlık kayıt sistemi”, sağlık alanında bilgi yönetimi söz konusu olduğunda, sık karşılaşılan kavramlardan biridir. Farklı kaynaklarda değişik şekilde tanımlanan ve bazı durumlarda birbirlerinin yerine kullanılan "elektronik hasta kaydı" (electronic patient record), "elektronik tıbbi kayıt" (electronic medical record), "bilgisayara dayalı hasta kaydı" (computer based patient record), "bilgisayara dayalı sağlık kaydı" (computer based health record), "elektronik sağlık kaydı" (electronic health record) gibi terimler, bu alanda kavram kargaşasına neden olmaktadır. Söz konusu terimlerin farklı biçimlerde kullanılması "Elektronik sağlık sistemleri" ile ilgili çalışmalarda karşılaşılan en önemli sorunlardan biridir (Hunter, 2002, s. 211). Elektronik sağlık kayıtlarının oluşturulması ve kullanılması sürecini kapsayan bu kavramlar; klinik sistemlerden ve veri setlerinden başlayan, sürekli gelişim göstererek elektronik sağlık kayıtlarına kadar uzanan aşamalar içerisinde değerlendirilir (Amatayakul, 1998).

Bu çalışma kapsamında elektronik sağlık kayıt sistemi, kullanıcıları desteklemek üzere özel olarak tasarlanmış, doğru ve eksiksiz verilere, uyarılara, yönlendirmelere, klinik karar destek sistemlerine ve tıbbi bilgiye erişimi sağlayan bir sistem olarak ele alınmaktadır (Dick, Steen ve Detmer, 1997, s. 55). Aynı zamanda bu sistemler klinik ve idari verilerin bütünleşik bir biçimde kullanılabildiği hastane enformasyon sisteminin bir parçasını oluşturmaktadır (Dick, Steen ve Detmer, 1997, s. 56). Sistemde bilgiye gereksinim 
duyulduğu yerde ve zamanda, gerekli gizlilik ve güvenlik kuralları çerçevesinde erişim sağlanması hedeflenmektedir.

İdeal bir elektronik sağılk kayıt sisteminde, hastanın tedavisi/bakımı sırasında gereksinim duyulan hasta kabul, taburcu ve transfer işlemleri gibi idari uygulamalar ve klinik uygulamalara ilişkin bilgiler bir ağ yapısı üzerinde bir arada tutulabilmektedir (Bkz. Şekil 1).

Şekil 1. Elektronik Sağlık Kayıt Sistemi (Shortliffe ve Blois, 2001, s. 11).

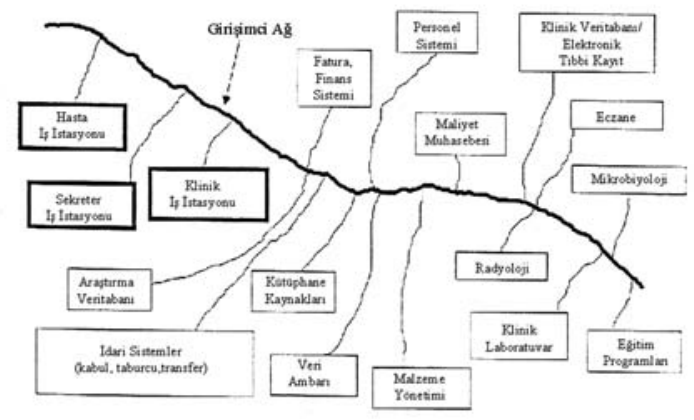

Sistem içinde, sağlık çalışanlarına (hekim, hemşire, diyetisyen, fizyoterapist, eczacı, sağlık teknikeri vb.) klinik uygulamalarda, bir başka deyişle, hastanın tanı ve tedavisinde yardımcı olabilecek, daha doğru karar vermesini sağlayabilecek ve yönlendirebilecek programlar da geliştirilmiştir. Klinik karar destek sistemleri olarak adlandırılan bu programlar sağlık çalışanlarına hastalığın tanı ve tedavisinde; klinik tanı süreçlerinin maliyeti, ilaç etkileşimleri ve ilaç alerjileri hakkında bilgi verme, alternatif testler ve tedaviler önerme gibi birçok farklı şekilde destek sağlayabilmektedir (Wigertz, 1995, ss. 15-20; Office of Technology, 1995, s. 124 ; Anderson, 1997, ss. 83-89 ; Metzger, 1995, ss.14-16). Bu tür sistemlerde ayrıca dış veri kaynakları olarak adlandırılan danışma kaynaklarını, bibliyografik ve tam metin veri tabanlarını kapsayan elektronik kütüphanelere ve internet bilgi kaynaklarına erişim sağlanmaktadır. Ayrıca sağlık çalışanları hasta kayıtlarından, hasta bakımına yönelik bilgilere kolayca ulaşabilirken; sistem ile bütünleşik olarak hizmet veren "elektronik kütüphane" kaynaklarından da literatür taramasını yapabilmekte ve ilgili literatüre hızla erişebilmektedir.

Sağlık çalışanlarının hastanın tedavisi/bakımı için gereksinim duyduğu literatür bilgisine ulaşmasını sağlayan sistemlerin, elektronik sağlık kayıt sistemleri ile bütünleşik olarak hizmete sunulması aşağıdaki alanlarda yarar sağlamaktadır: 
> Sağlık çalışanlarının bilgi kaynaklarına daha kısa zamanda ve daha az maliyetle ulaşımına olanak tanır. Bu sistem, sağıı çalışanlarının bilgi edinmek için sıkça başvurduğu dizinler, öz dergiler, makaleler, danışma kaynakları ve kitaplar gibi bilgi kaynaklarına erişmesini kolaylaştırmakta; tarama, kaynağı bulma, kopyalama, yorumlama gibi işlemlerin daha kısa süre içinde yapılmasını mümkün kılmaktadır.

> Sağlık çalışanları için, her geçen gün sayısı hızla artan özellikle web sayfalarından kolaylıkla erişilebilen tıbbi bilginin taranması, elenmesi ve klinik uygulamalarda kanıt olarak yorumlanmasındaki güçlükleri ortadan kaldırarak, elenmiş ve güvenilir bilginin kolaylıkla elde edilmesi sağlanmaktadır.

> Sağlık hizmetlerinde giderek artan maliyetlerin düşürülmesi önemli konulardan birisidir. Sağlık çalışanlarının tanı ve tedavi için gereksinim duyduğu literatüre hızı erişmesi hastanın hastane kaynaklarını kullanma sürecini (yatış süresi gibi) azaltacağı için genel anlamda sağlık giderlerinin maliyetini düşürecektir.

\section{Elektronik Sağlık Kayıt Sistemleri ve Elektronik Tıp Kütüphaneleri}

Bilginin hızla artışı, teknoloji ve kullanıcı gereksinimlerindeki değişim kütüphanelerin geleneksel yapılarını değişikliğe uğratmış ve "elektronik kütüphane" gibi kavramların ortaya çıkmasına neden olmuştur.

Kütüphane hizmetlerinin bilgi, bilgisayar ve ağ teknolojilerine dayalı olarak elektronik ortamda verildiği; elektronik kaynakların, elektronik ortamda düzenlendiği ve hizmete sunulduğu, ayrıca, geleneksel basılı veya baskı dışı kaynakların da yer alabildiği bir sistemi tanımlayan elektronik kütüphane kavramı (Subaşığlu, 2001, s. 45) "sayısal kütüphane" ve "sanal kütüphane" olarak adlandırılan kütüphane türlerini de kapsayan genel bir terim olarak değerlendirilmektedir (Yalvaç, 2001, s. 48).

Bütünleşik elektronik sağlık kayıt sistemlerinde dış veri kaynağı olarak tanımlanan elektronik kütüphaneler, sağlık çalışanlarının hastanın tanı/tedavisi sırasında gereksinim duyduğu literatür bilgisine hızla ve güvenilir olarak erişimini sağlamaktadır. Bu sistemden sağlık çalışanları klinik içerisinde sıkça karşılaştığı (herhangi bir durumda önerilecek testler, son tedavi uygulamaları, ilaçların sebep olduğu semptomlar gibi) ancak çoğu zaman yanıtını bulamadığı veya diğer meslektaşlarından bilgi edinmeye çalıştığı sorularının yanıtını güvenilir bilgi kaynaklarından doğrudan ve hızlı biçimde alması mümkün olabilmektedir (Sujansky, 1998, ss. 176-183). 
Literatürde, bütünleşik elektronik sağlık kayıt sistemleri için farklı modellerin geliştirildiği görülmektedir. Smith (1998, s. 13) elektronik sağlık kayıt sistemi için dört veri tabanı oluşturulmasını önermektedir. Bunlardan birincisi tıbbi bilginin bir bütün olarak görülmesine olanak sağlayacak şekilde düzenlenir. Sağlık çalışanı, hangi hastalık hangi belirtileri taşır, önerilen tedavi nedir, ilaç dozajları ve yan etkileri nelerdir gibi soruların yanıtını bu veri tabanından bulabilmektedir. İkinci veri tabanı, sağlık çalışanlarının deneyimlerinden oluşur. Hastalığın tanı ve tedavisine ilişkin bilgilerin bulunduğu bu veri tabanı, benzer durumlarda sisteme başvuran sağlık çalışanına hasta tedavisinde izleyeceği yol konusunda fikir verir. Sistem içinde yer alması önerilen üçüncü veri tabanı, bireysel hasta kayıtlarını içerir. Hastaya ait kişisel bilgilere hızlı erişilmesini sağlayarak sağlık çalışanına zaman kazandırır. Dördüncü veri tabanı ise, kütüphanecilerin sağlık çalışanı ve hasta için bilgi bulmakta kullandıkları dizinleri ve öz dergilerini, temel tıp kitaplarını, danışma kaynaklarını ve tam metin veri tabanlarını içeren elektronik kütüphane kaynaklarından oluşmaktadır. Sistem mevcut hasta kayıtlarını kullanarak sağlık çalışanın araştırdığı konuya ilişkin oluşturduğu arama stratejisini sadeleştirir ve "elektronik sağlık kayıt sisteminde" bulunan veri tabanları arasında oluşturulan arayüz yardımıyla tarama sonuçlarını getirir (Smith, 1998, s. 12).

Bütünleşik elektronik sağlık kayıt sistemlerinde, sağlık çalışanının tanı ve tedavi için gereksinim duyacağı hastanın tıbbi geçmişi ve hastanın o andaki durumuyla ilgili genel tıbbi bilgiler ile birlikte duruma uygun literatür bilgileri de çevrimiçi olarak erişime sunulmaktadır. Sağılı çalışanının hasta bakımı esnasında gereksinim duyduğu yanıtları bulabilmesini sağlayan ve temel hedefi "karar verme noktasında bilgilenme" olarak tanımlanan (Fuller, 1999, s. 394) tıbbi bilgi hizmetleri, elektronik sağlık kayıt sistemleri ile elektronik kütüphanelerin bir arada kullanılması ile gerçekleşmektedir.

Tıp ve sağlık alanında ABD'de 1980'lerin başlarında oluşturulan ve bu alandaki bilgi yönetiminin ilk örneklerinden biri olarak değerlendirilen "Bütünleşik Akademik Enformasyon Sistemleri" (Integrated Academic Information Management Systems-IAIMS) halen bu ülkede yaygın olarak kullanılmaktadır. Amerikan Ulusal Tıp Kütüphanesinin (National Library of Medicine-NLM) desteği ile 1983'te uygulamaya geçirilen sistem, temelde akademik tıp ve sağlık bilimleri merkezlerinde bütünleşik enformasyon sistemlerini geliştirmek üzere tasarlanmakla birlikte, hastanelerde de uygulanmaya başlanmıştır. Sistem, hasta kayıtlarını, laboratuvar testlerini, klinik bilgilerini, klinik karar sistemlerini, araştırma sonuçlarını, sağılıla ilgili verileri ve enformasyonu bibliyografik veri tabanlarıyla bütünleştirerek sunma olanağı sağlamaktadır (Alkan, 2003, s. 133). 
Tıp literatüründe araştırmaya olanak veren ve makalelerin bibliyografik kayıtlarını veya tam metnini içeren çevrimiçi sistemlerin sayısında her geçen gün artış görülmekte ve "Elektronik sağlık kayıt sistemleri" ile ilişkilendirilmesi önerilen bibliyografik veri tabanları arasında öncelikle MEDLINE (Medical Literature, Analysis, and Retrieval System Online) yer almaktadır (Sujansky, 1998, ss. 176-183).

Cimino (1996, s. 125) bu tür bütünleşik sistemlerin bibliyografik bilgi ve dergi makalelerinin tam metni dışında diğer bilgi kaynaklarını da barındırması gerektiğini vurgulamaktadır. Elektronik sağlık kayıt sistemlerinde sağlık çalışanının hasta bakımına yönelik sorularının yanıtları için sıkça kullandığı MEDLINE ve diğer bibliyografik veri tabanlarının yanısıra tam metin içeren bilgi hizmeti sağlayıcıları (OVID, Ebsco Host, Gale-Health \& Wellness ve OCLC gibi) ve tam metin veri tabanları da (Proquest, Springer Link, Science Direct-Ideal, Blackwell Synergy, Wiley InterScience gibi) yer almalıdır. Ayrıca ilaç danışma kaynakları (Mikromedex gibi) ve elektronik kitapların yanısıra elektronik olarak erişilemeyen makaleler için, makalenin siparişini ve en kısa zamanda kopyasının gelmesini sağlayacak belge sağlama hizmetlerinin de yer alması gereklidir.

Sağlık bilgi yönetimi ve kütüphanecilik kavramlarını bir araya getiren ve sağlık çalışanın bilgi edinme sürecinde karşılaştığı pek çok sorununu çözebilecek bu uygulamalar; sağlık çalışanları, tıp bilişimcileri, tıp kütüphanecileri, dil bilimciler gibi farklı disiplinlerden oluşan bir ekibin eşgüdüm içinde çalışmasını gerektirmektedir (Betsy, 2000, s. 452).

\section{Türkiye'de Durum}

Türkiye'de sağlık sektörüne genel olarak bakıldığında sağlık kurumlarında sağılılı bir bilgi sisteminin olmadığı, gerek kurum içinde gerekse kurumlar arasında yeterli düzeyde bilgi alışverişi yapılamadığı, ülke genelinde sağlık verilerinin yetersiz ve düzensiz olduğu kalkınma planlarında ifade edilmektedir (Devlet, 2001, s. 18).

Yaşanan bu olumsuzlukları gidermek amacıyla ulusal düzeyde bir bilgi sisteminin oluşturulması, sağlık sektörünün beklentilerinin karşılanması ve e-Avrupa kapsamında e-sağlık hedeflerini gerçekleştirmek üzere Sağlık Bakanlığının eşgüdümünde e-sağlık çalışma grupları oluşturulmuştur. Çalışma gruplarının raporları sonucunda ortaya konan "Türkiye Sağlık Bilgi Sistemi Eylem Planı " Ocak 2004 tarihinde yayımlanarak uygulamaya konulmuştur. Bu plan ile toplumun sağlığının korunması ve geliştirilmesi için bilgi ve iletişim teknolojilerinin sağlık alanında etkin ve verimli bir şekilde kulanımını sağlayarak, erişim hakları tanımlanmış, yetkili kişi ve kuruluşlarca 
ulaşılabilir, her bireyin sağlıkla ilgili güncel ve doğru bilgiler ile kendi bilgilerine erişebildiği, doğum ile başlayıp tüm yaşam boyu oluşan sağlıkla ilgili verilerin tüm ülkeyi kapsayacak sağlık özel ağı üzerinden paylaşılması hedeflenmektedir (Sağlık Bakanlığı, 2004, s. 39). Sağlık Bakanlığının bu konuda çalışmaları devam etmektedir.

Tıp ve sağlık kütüphaneciliğinde yaşanan gelişmelere baktığımızda ise, bilgi yönetimi ve bilgi teknolojileri alanında yaşanan değişimin kütüphaneleri ve kütüphanecilik uygulamalarını da etkilediği görülmektedir. Teknolojik olanaklardan yararlanarak yeniden yapılanma sürecine giren tıp kütüphanelerinde, çevrimiçi kataloglar, internet, makalelere elektronik olarak erişim sağlayan tam metin veri tabanları, bibliyografik veri tabanları, elektronik kitaplar vb. kullanılarak birçok elektronik kaynaklarla çağdaş hizmetler sunulmaktadır (Alkan, 2002, s. 29). Bu hizmetlerin sayısının ve niteliğinin her geçen gün artması ve konsorsiyumlar oluşturularak bilgi sağlama sürecinde işbirliği yapılması da yararlanma olanaklarını artırmaktadır.

Bu uygulamalara örnek olarak kütüphanelerin bağlı bulunduğu kurum içerisinden erişime açılabilen ve tıp kütüphanelerinin de üyesi olduğu Anadolu Üniversite Kütüphaneleri Konsorsiyumu (ANKOS) ${ }^{*}$ verilebilir. ANKOS kapsamında Web of Science (WoS), OVID, EBSCOhost, Proquest, Science Direct-Ideal, Blackwell Synergy, Springer Link-Kluwer, Gale Health and Wellness, Wiley Interscience, Oxford University Press gibi farklı tıp yayın evlerinin sunduğu elektronik yayınlarına erişilebilen bibliyografik ve tam metin veri tabanları yer almaktadır. Ayrıca Üniversite ve Araştırma Kütüphanecileri Derneği (ÜNAK) tarafından yapılan ÜNAK/OCLC Konsorsiyumunda ${ }^{*}$ da tıp kütüphaneleri kapsanmaktadır. OCLC'nin danışma hizmeti FirstSearch'de MEDLINE'nın yanısıra makalelere, bildirilere, $\mathrm{ABD}$ resmi yayınları ile kitaplara, kitap dışı kaynaklara ve e-kaynaklara da bibliyografik ve/veya tam metin erişim sağlanmaktadır.

Ayrıca TÜBITAK/ULAKBiM tarafından Türk Tıp Dizini oluşturulmuştur. Türk Tıp Dizini, sağlık bilimleri alanında Türkiye'de yayımlanan süreli yayınlardaki Türkçe ve diğer dillerdeki makaleleri içerir. Türk Tıp Dizini'ne alınan makaleler, genellikle üniversite ve araştırma hastanelerinde yapılan özgün çalışmaları kapsamaktadır.

Türk Tıp Dizini 1994, 1995, 1996, 1997 yılları arası basılı olarak yayınlanmıştır. 2001 yılından itibaren, Türk Tıp Dizinindeki kayıtlardan

\footnotetext{
*ANKOS. (2003). 22 Şubat 2004 tarihinde ANKOS Web sitesinden erişildi: http://www.lib.metu.edu.tr/ankos/

** ÜNAK. (2004). UNAK/OCLC Konsorsiyumu, 24 Şubat 2004 tarihinde ÜNAK Web sitesinden erişildi: http.//www.unak.org.tr/unakoclc/ 
makalelerin birçoğunun özetine ve tam metinlerine elektronik ortamda erişim olanağı sağlanmıştır. Dizinleme için MESH (MEdical Subject Headings) konu başlıkları kullanılmaktadır. Türk Tıp Dizini'nin Tıp Enformasyonunun kalitesine yaptığı en büyük katkı "Dergilerin Türk Tıp Dizini'ne alınma kriterlerindeki bağlayıcı hükümler olmuştur. Bu kıstaslar çerçevesinde dergilerin düzenli zaman aralıklarında yayınlanması, dergilerdeki hakem değerlendirme sisteminin belirlenen koşullara uygunluğu dergilerdeki araştırma makaleleri sayısının \%50'sini oluşturma koşulu, makalelerde İngilizce ve Türkçe başlıkların bulunma zorunluluğu, anahtar sözcüklerin verilmesi gereği, dergilerin yıllık dizinlerinin mecburiyeti, tıp dergi yayıncılığına en azından "standartlara" uyma kaygusunu getirmiş̧ir (Yıldızeli ve Tabanlıoğlu, 2002).

Bu kriterler çerçevesinde Tıp dergilerinin fiziksel niteliklerinde önemli bir gelişme gözlenmiştir. Türk Tıp Dizini'nin ortaya çıkışından sonra yayın hayatına başlayan dergilerde gerek itinalı baskı gibi fiziksel nitelikler, gerekse bibliyografik künye, alıntılar, İngilizce/Türkçe başlık ve öz gibi içeriksel niteliklerde çok olumlu gelişmeler gözlenmiştir. Ayrıca yine "Dergi Seçim Kriterleri'nin" getirdiği zorlayıcılık, bazı dergilerde hakemlik müessesesinin gelişmiş ülkelerdeki benzer ciddi bir platforma çekilmesine neden olmuştur. Kriterlerdeki bir madde ile "dergilerde kesinlikle hakem değerlendirme sistemi bulunmalı ve bu değerlendirmelerin, Türk Tıp Dizini Oluşturma Kurulu tarafından ilgili yıl içerisinde rastgele (tesadüfi) yöntemle seçilen bir veya birkaç makalenin hakem raporlarının Kurulca denetlenmesine olanak verilecek biçimde saklanması" öngörülmektedir ki, bu oldukça önemli bir kalite yaptırımıdır (Yıldızeli ve Tabanlıoğlu, 2002).

Bütün bu olumlu özelliklerin yanısıra Türk Tıp Dizini'nin en büyük sorunu ise, günceli yakalayamamasıdır. Sağlık bilimleri gibi devamlı yeni araştırmaların yapıldığı ve gelişmelerin olduğu bir alanda güncellik oldukça önemli bir özelliktir.

\section{Sonuç ve Öneriler}

Kütüphanelerin elektronik sağlık kayıt sistemleri ile ilişkilendirilmesi, bilgi hizmetlerinin temeli olan gereksinim duyulan bilgiye erişimi sağlamak amacını gerçekleştirecektir. Ülkemizde tıp kütüphaneleri en kısa zamanda elektronik kütüphane kavramını yakalamak zorundadırlar. Gelecekte sağlık hizmetlerinde yaygın olarak kullanılacak olan elektronik sağlık kayıt sistemlerinde tıp kütüphanelerin yer alabilmeleri dünyadaki gelişmelere uygun olarak altyapılarını ve koleksiyonlarını geliştirmelerine bağlıdır.

Disiplinlerarası bir uygulama olan ve eşgüdümlü bir çalışmayı gerektiren elektronik sağlık kayıt sistemleri ile bütünleşik elektronik kütüphanelerin 
geliştirilmesi; kütüphaneciler, sağlık çalışanları, sağlık yöneticileri, tıbbi belge bilimciler ve arşivciler, tıp bilişimcileri vb. birden fazla bilim alanının kapsamına girmektedir. Birden çok disiplini bir araya getiren bu uygulamalarda tıp kütüphanecilerimizin değişen bilgi hizmetleri alanında yerlerini almaları/alabilmeleri kendilerini yenilemelerine ve kendilerinden beklenen rolü oynayabilmelerine bağlı olacaktır. Öte yandan ülkemizde henüz altyapı hazırlıkları devam eden elektronik sağlık kayıt sistemlerinin tasarlanması, sağlık hizmetlerinde yaşanan değişimlere ve dünyadaki gelişmelere uygun olmalıdır. Kuşkusuz başlangıçta alınacak böyle bir önlem, kaynakların daha verimli ve etkin kullanılmasını da sağlayacaktır.

\section{Kaynakça}

Alkan, N. (2002). Günümüzde tıp ve sağlık bilimleri kütüphaneciliği. F. RukanCı ve diğerleri [Yay. Haz.]. "Elektronik Gelişmeler Işığında Araştırma Kütüphaneleri” Sempozyumu bildirileri: 24-26 Ekim 2002-Bolu içinde (ss. 17-33). Bolu: Abant İzzet Baysal Üniversitesi.

Alkan, N. (2003). Tıp ve sağlık kuruluşlarında bilgi yönetimi. Bilgi Dünyası, 4 (2), 122-145.

Amatayakul, M. (1998) The state of the computer based patient record. Journal of American Health Information Management Assocation, 69 (9), 34-40, guiz, 43-44.

Anderson, J.G. (1997). Health care information system. Communication of the ACM, 40 (8), 83-89.

ANKOS. (2003). 22 Şubat 2004 tarihinde ANKOS Web sitesinden erişildi: http://wwww.lib.metu.edu.tr/ankos/

Betsy, L. (2000). Electronic health record meets digital library a new environment for achieving an old goal. JAMIA, 7 (5), 44-452.

Bozkurt, V. (1997). Enformasyon toplumu ve Türkiye. İstanbul: Sistem Yayıncılık.

Cimino, J.J. (1996). Linking patient information systems to bibliographic resources. Methods of Information in Medicine, 35 (2), 122-126.

Devlet Planlama Teşkilatı, Sağlık Hizmetlerinde Etkinlik Özel İhtisas Komisyonu. (2001). Sağlık hizmetlerinde etkinlik özel ihtisas komisyon raporu (Rapor No: DPT/2561/ÖiK/ 577). Ankara: DPT. 
Dick, S.R., Steen, E.B. ve Detmer, D.D. (1997). The computer based patient record an essential technology for health care. Washington, DC: National Academy Press.

Dienemann, J. ve Van De Castle, B. (2002). The impact of health care informatics on the organization. S.P. Englebardt ve R. Nelson (Eds.). Health Care Informatics: An Interdisiplinary Approach içinde. (ss. 303-320). St. Louis: Mosby.

Erdoğan, İ.(2000).Değişim hızlanıyor. Modern Hastane Yönetimi Dergisi, 4, 1.

Fuller, S.S. (1999). Integrating knowledge resources at the point of care: Opportunities for librarians. Bulletin of Medical Library Association, 87 (4), 393-403.

Hacettepe Üniversitesi Kütüphaneleri. (2003). Elektronik kaynaklar A'dan Z'ye. 12 Şubat 2004 tarihinde Hacettepe Üniversitesi Web sitesinden erişildi: http://www.library.hacettepe.edu.tr/a-z.htm

Hunter, K.M. (2002). Electronic health records. S.P. Englebardt ve R. Nelson (Eds.) Health Care Informatics içinde (ss. 210-230). St. Louis: Mosby.

Metzger, J.B. (1995). The potential contributions of patient care information system. Erica L. Drazen ... [et al.] with contributions by John p. Glaser ... [et al.]. Patient Care Information Systems: Successful Design and Implementation içinde (ss. 14-16). New York: Springer-Verlag.

Office of Technology Assessment, Congress of the United States. (1995). Bringing health care online: The role of information technologies. Washington, DC: U.S. Congress, Office of Technology Assessment.

Sağlık Bakanlığı. (2004). Türkiye sağlık bilgi sistemi eylem planı. 27 Nisan 2004 tarihinde Sağlık Bakanlığı Web sitesinden erişildi: http://www.saglik.gov.tr/sb/tsbs/default.asp?t=belgeler

Shortliffe, E.H. ve Blois, M.S. (2001). The computer meets medicine and biology: Emergence of a discipline. E.H. Shortliffe ve L.E. Perreault (Eds.). Medical Informatics Computer: Computer Applications in Health Care and Biomedicine içinde (s. 11). New York: Springer.

Sloane, R.M. ve Sloane, B.L. (1992). A guide to health care facilities (3rd ed.). Michigan: Health Administration Press.

Smith, S.E. (1998). Patient record key to medical searching. Information Today, 15 (4), 12-15. 
Subaşıŏlu, F. (2001). Dijital kütüphaneler: Tanımlama sorunu. Türk Kütüphaneciliği, 15 (1), 45-54.

Sujansky, V.W. (1998). The benefits and challenges of an electronic medical record: Much more than a word-processed patient chart. Western Journal of Medicine, 169 (3), 176-183.

ÜNAK. (2004). 24 Şubat 2004 tarihinde ÜNAK Web sitesinden erişildi: http://www.unak.org.tr/unakoclc/

Wigertz, O. (1995). Clinical decision support-how when and for whom. Computer Methods and Programs in Biomedicine, 48 (1-2), 15-20.

Yalvaç, M. (2001). Web’te enformasyon okur yazarlığı. Bilgi Dünyası, 2 (1), 48-60.

Yıldızeli, A. ve Tabanlıoğlu, S. (2002). Türk Tıp Dizini'nin Türk enformasyon sistemine katkıları. Bilgi Dünyası, 3 (1), 45-60.

\section{Yardımcı Kaynakça}

Detmer, D.E. ve Steen, E.B (1993). Patient record in the information age. Issues in Science and Technology, 9 (3), 24-27.

Johnson, G.K. (1994). Functional requirement of a computer based patient record system. Healthcare Financial Management, 48 (6), 54-58.

Mendonça, E.A. (2001). Building a knowledge base to support a digital library. V.L. Patel, R. Rogers ve R. Haux (Eds.). MEDINFO 2001 içinde (ss. 221-225). Amsterdam: IOS.

Morton, L.T. ve Godbolt, S. (1992). Information sources in the medical sciences (4th ed.). London: Bowker-Saur.

Murphy, G.F. (2001). Electronic health records: A unifying principle. M. Abdelhak, S. Grostick, M.A. Hanken, ve E. Jacobs. Health Information: Management of a Strategic Resource (2nd ed.) içinde (ss. 688-712). Philadelphia: W.B. Saunders Company.

Smith, R. (1996). What clinical information do doctors need? BMJ, 313 (7064), 1062-1068.

Waegemann, C.P. (1998). Where are we on the road towards EPR system? Tutorial, Toward an Electronic Patient Record, 98.

Wyatt, C.J. (1995). Hospital information management: The need for clinical leadeership. BMJ, 311 (6998), 175-176. 